\title{
THE CONTROL OF RATS LIVING BETWEEN ACCESS POINTS IN SEWERS
}

\author{
By E. W. BENTLEY, A. H. BATHARD AND J. D. RILEY \\ Infestation Control Division, Ministry of Agriculture, Fisheries and Food, \\ Tolworth, Surbiton, Surrey
}

(With 2 Figures in the Text)

\section{INTRODUCTION}

The usual method of controlling rats in sewers in England and Wales is to lay poison bait, twice yearly, at the manholes. In a previous study (Bentley, Bathard \& Hammond, 1955) it has been shown that in at least one type of sewer this course is unlikely to result in complete extermination of the rodent population because some animals seem to live mainly between manholes and are thus unlikely to come into contact with the poison. It has been suggested (Bentley, 1955) that the existence of these 'intermanhole' rats may be due to territorial behaviour. If this were so, it might be expected that elimination of the animals living near the manholes would soon be followed by territorial expansion on the part of the survivors. One or more suitably timed, further poisonings might then remove enough of these to delay appreciably the recovery of the population, and where the manholes are not too far apart, might even give complete control. An attempt to put this theory to the test is described below.

\section{METHODS}

As in the previous investigation, the sewer selected was an L.C.C. main drain of brick-barrelled construction and about $2150 \mathrm{ft}$. long (Fig. 1). The ovoid was $4 \mathrm{ft}$. high and $2 \mathrm{ft} .8 \mathrm{in}$. wide except where the drain passed under a railway. There it narrowed to $3 \mathrm{ft} .8 \mathrm{in}$. by $2 \mathrm{ft}$. Both ends of the sewer ran into an even larger drain where the flow was too deep and fast for rats to pass. Along the sewer were seven side-entrances (S1-7), but the last one at the south-east end (S7) was frequently flooded. No rats appeared to be living near it and observations were eventually confined to S1-6.

Another brick-barrel ran into the sewer near $\mathrm{S} 1$ at a distance of $230 \mathrm{ft}$. from the north-west end. It soon became clear that no rats were living in the proximal section and subsequent observations showed that few, if any, rats migrated into the experimental stretch by this route during the period of the study.

Of more importance were five entrant pipe-sewers and each of these, as far as the second or third manhole along (M 1-14), was included in the experimental area.

The district above-ground had suffered some bomb damage. It consisted of railway property, shops, factories and terrace-type houses, many of them converted into small workshops connected with the furniture-making trade. A feature of the district also was a popular Sunday market from which food refuse probably 
found its way into the sewer. The flow in the main drain was fairly small and slow at most times of the day and rats would have had little difficulty in moving about. As in the previous experiment, a week or so before observations began, metal bait-trays (T 1-63) were fixed to the walls of the main drain. They were distributed along a stretch of $1912 \mathrm{ft}$. between the north-west end and S5, and were sited where rats were most likely to find them; they were thus sometimes more, sometimes less, than $30 \mathrm{ft}$. apart.

In the initial phase of the experiment an attempt was made to free the manholes and side-entrances of rats by poison baiting with sodium fluoracetate. Census baits were then maintained at these points to detect any outward movement of animals still living in the intermanhole sections of the sewer and any immigration from outside the study area. Rats appearing at the outermost manholes were regarded as immigrants and were eliminated as soon as possible. Further details of the procedure adopted are given below.

\section{RESULTS}

The first operation, beginning on 6 July, was a bait-census with dry wheat at the manholes and side-entrances and also along the main drain. This went on for 15 days, during the last four of which the average total 'take' for the main drain, its side-entrances and the first manhole along each sideline was $1148 \mathrm{~g}$. and for the outer manholes $437.5 \mathrm{~g}$. If it is assumed that the population was fully baited (and previous experience of similar sewers suggests that quite possibly this may not have been so) these figures indicate that in and around the main sewer there were about forty-five medium-sized rats (or their equivalent biomass), and in the whole system at least sixty to sixty-five animals. The average 'takes' during the last 4 days at the individual baiting points are given in Fig. 1. They show that the rats were fairly well spread along the whole $1912 \mathrm{ft}$. of the main drain and in three of the five side-lines. Further, the population seemed to consist of several separate colonies. For example, at least seven or eight rats fed regularly at T62 (where, on days 12 and 13 , takes of $190 \mathrm{~g}$. were recorded), whereas no 'takes' occurred at T 59-61, T 63 and S5. In fact, no 'takes' were recorded at these points on any census day except at $\mathbf{T} 63$ on day 1 , when $15 \mathrm{~g}$. of wheat disappeared. For similar reasons it may be deduced that separate families of rats were centred around T9, T 26, T 35 and T 57. In general, therefore, the animals were distributed in much the same way as the population previously reported upon, and also, as the rat population of the Stuttgart sewer studied by Peters (1951).

In the middle of the census-in order to find out more about the distribution of colonies-dyed bait was laid at four points that had been showing large 'takes'. A different dye was used at each point. Unfortunately, three of the dyes appeared to be unpalatable and an appreciable amount of coloured bait was eaten only at T9. Droppings from rats that had fed at this tray were found at T 2, S1, T9, T 10 and $\mathrm{T} 16$. $\mathrm{T} 2$ was $255 \mathrm{ft}$. from $\mathrm{T} 9$ and $\mathrm{T} 16$ was $215 \mathrm{ft}$. in the opposite direction. It is doubtful if there was as much rat movement as this elsewhere in the sewer.

The total 'takes' during each $24 \mathrm{hr}$. of the census are given in Table 1 . The peak 


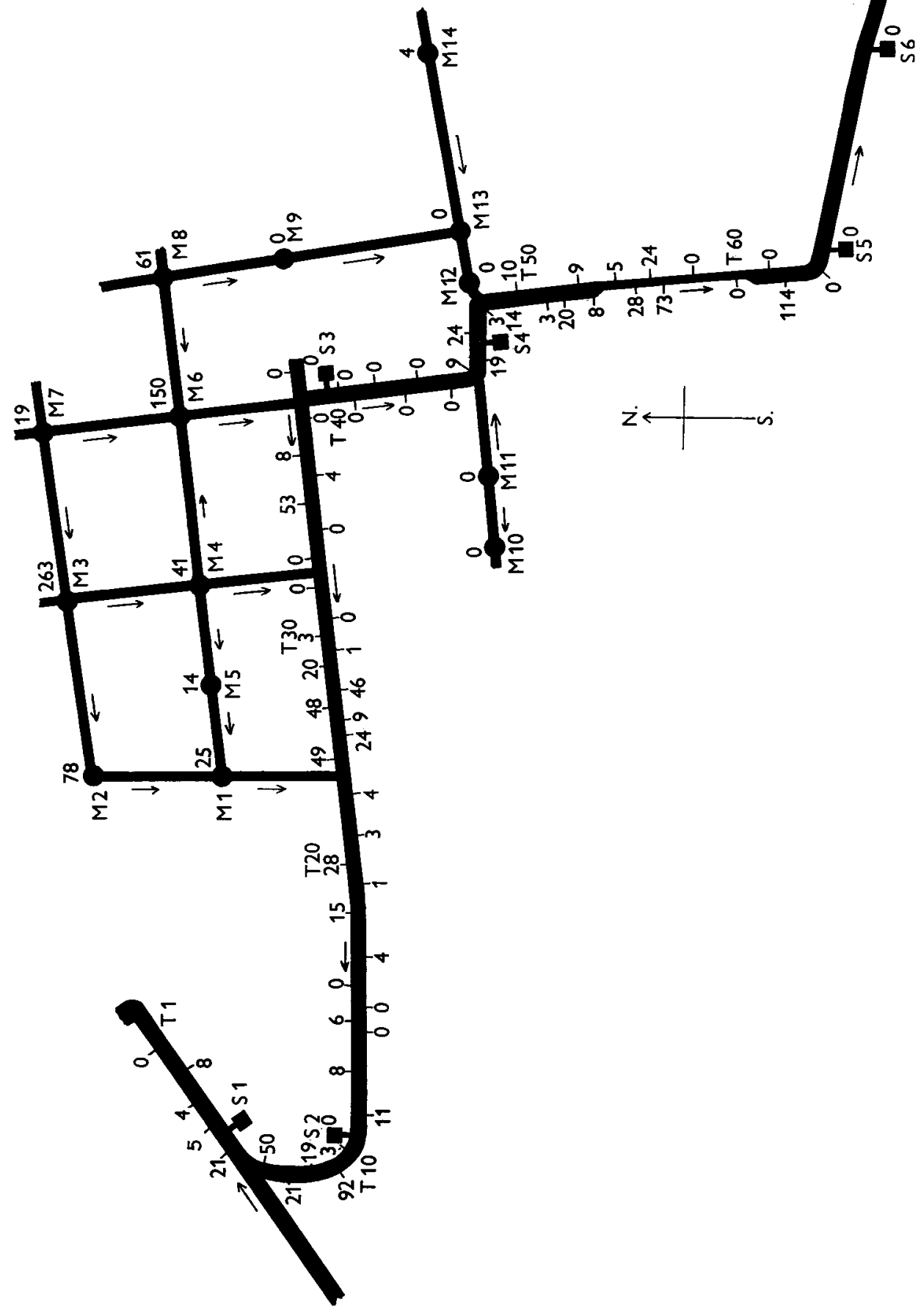


'take' occurred on day 12 both on the trays and at the access points and the average 'take' for, say, days 9-12 was somewhat higher than that for days 4-6, although the bait was partly carried to the rats by laying it along the sewer. This suggests once again that, in some sewer systems, if the prebaiting period in control treatments can be extended beyond the normal 3-5 days, better results can be expected (Bentley, et al. 1955; Bentley, 1956).

Table 1. Total daily 'take' (grammes) of wheat during the first census

\begin{tabular}{|c|c|c|c|c|c|c|c|c|c|c|c|c|c|c|c|c|}
\hline \multirow[b]{2}{*}{ Points } & \multicolumn{15}{|c|}{ Day } & \multirow{2}{*}{$\begin{array}{c}\text { Av. of } \\
\text { days } \\
12-15\end{array}$} \\
\hline & 1 & 2 & 3 & 4 & 5 & 6 & 7 & 8 & 9 & 10 & 11 & 12 & 13 & 14 & 15 & \\
\hline Duter manholes & 110 & 140 & 155 & 235 & 255 & 340 & 305 & 280 & 235 & 310 & 290 & 445 & 440 & 415 & 450 & $437 \cdot 5$ \\
\hline $\begin{array}{l}\text { Inner manholes } \\
\text { and side en- } \\
\text { trances }\end{array}$ & 35 & 70 & 155 & 185 & 150 & 135 & 145 & 145 & 205 & 180 & 240 & 265 & 250 & 195 & 210 & 230 \\
\hline Trays along sewer & 520 & 400 & 575 & 760 & 600 & 595 & 630 & 530 & 725 & 915 & 740 & 1008 & 905 & 905 & 855 & 918 \\
\hline $\begin{array}{l}\text { Total (less outer } \\
\text { manholes) }\end{array}$ & 555 & 470 & 730 & $94 \tilde{5}$ & 750 & 730 & 775 & 675 & 930 & 1095 & 980 & 1273 & 1155 & 1100 & 1065 & 1148 \\
\hline
\end{tabular}

After the census all baits were removed and a gap of 12 days was allowed in order to minimize any effects of the operation on the normal feeding habits of the rat population. There then followed four consecutive poison treatments to eliminate all rats that were visiting the manholes and side-entrances. In the first treatment $0.3 \%$ sodium fluoracetate was left in position for 4 days, after prebaiting for only 2 days with damp coarse oatmeal. On the second prebaiting day the total 'take' of bait was $1115 \mathrm{~g}$. On the first day of poisoning $175 \mathrm{~g}$. of bait disappeared and a further $110 \mathrm{~g}$. went during the following 3 days. Since the average lethal dose of a bait containing $0.3 \%$ sodium fluoracetate for a rat of average size (200-300 g.) is only about $75 \mathrm{mg}$., this suggests that rats were coming to feed for the first time at the access points on the fourth day of the treatment or even later. Some may have been rats that had visited the baiting points earlier but had refused to feed; but it is hardly likely that many animals would have behaved in this way. The results of the first poison treatment, therefore, have a bearing on the question of whether to use bait preservatives in direct poisoning campaigns with sodium fluoracetate-if official approval is eventually given to this method of control of rats in sewers. It would appear that in some systems, at any rate, bait preservatives would increase efficiency.

The success of the first poison treatment may be roughly estimated from the prebait 'takes' of the second which began immediately afterwards. On this occasion boiled maize was the bait-case, of which only 25,55 and $45 \mathrm{~g}$. were eaten on days 1, 2 and 3, respectively. Since the 'take' of damp oatmeal on the second day of the first poison treatment totalled $115 \mathrm{~g}$. the kill was probably about 90 $95 \%$ of the rats visiting the access points.

The third and fourth poison treatments, using sausage rusk with $0.3 \%$ sodium fluoracetate and damp rusk with $2 \frac{1}{2} \%$ zinc phosphide, respectively, extended over about 21 days. During this time the maximum $24 \mathrm{hr}$. 'take' totalled $70 \mathrm{~g}$. Rat activity was apparent only at the outer ring of manholes - except at the side- 
entrance, $\mathbf{S} 2$ on the main sewer. Here no 'take' occurred throughout the 5 days of the second poison campaign and the first four of the third. On each of the two following days $45 \mathrm{~g}$. disappeared and on the next day a small amount of poison bait was taken. This was, therefore, the only apparent spreading-out of any intermanhole rats that may have escaped the previous poisonings. Probably, at the most, one or two animals were involved.

At this point it was decided to make a reconnaissance along the main drain. In order to alter the feeding habits of any survivors as little as possible, ten grains of wheat, only, were placed on each baiting tray and left for $48 \mathrm{hr}$. The results of this operation were unequivocal. No wheat was removed from trays 1-16. Seven grains disappeared from T 17 and all ten grains from T 18-63. This suggested that from $\mathrm{T} 17$ westwards the drain had been cleared, and that an unknown number of rats were still active from $\mathrm{T} 17$ eastwards. It is possible, however, that some of the rats, finding wheat on one or more trays at intervals along the sewer, were induced to visit other trays further afield. If this happened the normal range of the population may have been shorter than from $\mathrm{T} 17$ to $\mathrm{T} 63$. The removal of every grain of wheat (apart from those that may have been knocked into the sewer) from forty-six consecutive trays, located for the most part in complete darkness, illustrates vividly how little Rattus norvegicus depends on vision when searching for food.

On the day following the reconnaissance along the sewer, census baits of wheat were again laid at all manholes and side-entrances and examined 1, 3 and 5 days later. On the latter two occasions 'takes' of 50 and $30 \mathrm{~g}$. occurred at $\mathrm{S4}$, of 50 and $55 \mathrm{~g}$. at $\mathrm{S} 5$ and, apart from a mere $5 \mathrm{~g}$. 'take' at $\mathrm{S} 3$ during the second poison treatment, these were the first to be recorded at access points in this part of the system since the first poison treatment, which had ended 28 days before.

Table 2. Bait-'takes' (grammes) at the eastern end of the system 6 weeks after the first poisoning

\begin{tabular}{|c|c|c|c|c|c|}
\hline \multirow[b]{2}{*}{ Point } & \multicolumn{5}{|c|}{ Day } \\
\hline & 1 & 2 & 3 & 4 & 5 \\
\hline S 3 & 45 & 60 & 60 & 55 & 5 \\
\hline S4 & 0 & 0 & 0 & 0 & 30 \\
\hline S5 & 30 & 35 & 40 & 45 & 20 \\
\hline M11 & 0 & 0 & 0 & 0 & 10 \\
\hline M 12 & 10 & 0 & 5 & 0 & 0 \\
\hline Total & 85 & 95 & 105 & 100 & 65 \\
\hline
\end{tabular}

For the next 13 days no baits were laid at the inner manholes and side-entrances, but baiting, including poison baiting, continued at the outer manholes where two or three small 'takes', possibly due to immigrants, were occurring. There then followed 4 days of prebaiting at all access points with a damp oatmeal/sugar mixture, after which, $0.3 \%$ sodium fluoracetate in the same bait was left in position for 3 days. By this time a few rats had appeared at two more manholes and another side-entrance at the eastern end of the system (Table 2). 
In all perhaps six or seven rats were concerned, and the 'takes' at M 11, M 12 and $\mathrm{S} 4$ (on the poison day only) were probably due to the same one or two animals. The only other inner access point where a 'take' was recorded was at the opposite end of the sewer, at $\mathrm{S} 2$, where $10 \mathrm{~g}$. of poison bait disappeared.

Immediately after these operations a second reconnaissance took place along the main sewer using, as before, ten grains of wheat to each tray. Within $48 \mathrm{hr}$. all ten grains disappeared from T 6-9, eight grains from T 11 and all ten from T 12 to T47. Evidently the central part of the sewer was still infested and though no 'takes' occurred at T 48-63 later events suggested that even this end of the system still harboured a rat or two. The 'takes' at T 6-9 could have been due to immigration-possibly by a single rat from the brick-barrel sewer joining the system near T 5.

Before winding up the experiment any rats living between the access points were given one more opportunity to extend their territory. The inner manholes and side-entrances were left undisturbed for 4 weeks, but baits were maintained at the outer manholes and any rats that appeared were eliminated by a suitable poison. At the end of the 4 weeks prebaits were laid for 4 days at all access points and these were followed by poison baits, which were left in position for $72 \mathrm{hr}$. 'Takes' of prebait were recorded at only three places in the system, at M 6, S5 and $S 6$, and the amounts eaten at each point were within the capacity of one rat.

Finally, a full census took place at all manholes and side-entrances and along the sewer, beginning on the 126th day of the experiment and ending 8 days later. The average daily 'take' at the outer manholes during days 6-8 of the census was a mere $8 \mathrm{~g}$. At the access points in and around the main sewer the only 'take' was $10 \mathrm{~g}$. on day 7. The amounts eaten from the trays fixed along the sewer during the 8 days were: $290,380,487,455,510,595,460$ and $410 \mathrm{~g}$. Thus, the overall average 'take' during days 6-8 (excluding the outer manholes) was $475 \mathrm{~g}$. This may be compared either with $727 \mathrm{~g}$. which is the average for days 6-8 of the first census recorded in Table 1, or - less fairly perhaps-with the average for days 12-15, namely, $1148 \mathrm{~g}$. Thus, the rat population, after 19 weeks in which every effort was made to destroy it, except by baiting along the sewer itself, was estimated to be still $40-65 \%$ of its initial size.

Figure 2 shows that most of the population was now living between the side entrances, S2 and S3. It may or may not be coincidental that as in the previous study (Bentley et al. 1955) the 'takes' were greatest (at T26 and T27) where the distance to the nearest access point was the greatest ( $272 \mathrm{ft}$.). The only other points along the sewer where takes occurred were at T5, T40-2, T46, T48 and T58 and the amounts involved were small.

At the end of the final census the dry wheat that had been used was replaced by damp wheat, both at the access point and on the trays and on the next day (17 November), $0 \cdot 3 \%$ sodium fluoracetate was added. A poison 'take' of $153 \mathrm{~g}$. suggested that the treatment had been successful and in fact, twenty-nine bodies were subsequently picked up. Some of these were lying in the flow and others were discovered by poking into drains that entered the sewer from the surface. Thus, they probably represented a substantial percentage of the population-in contrast 


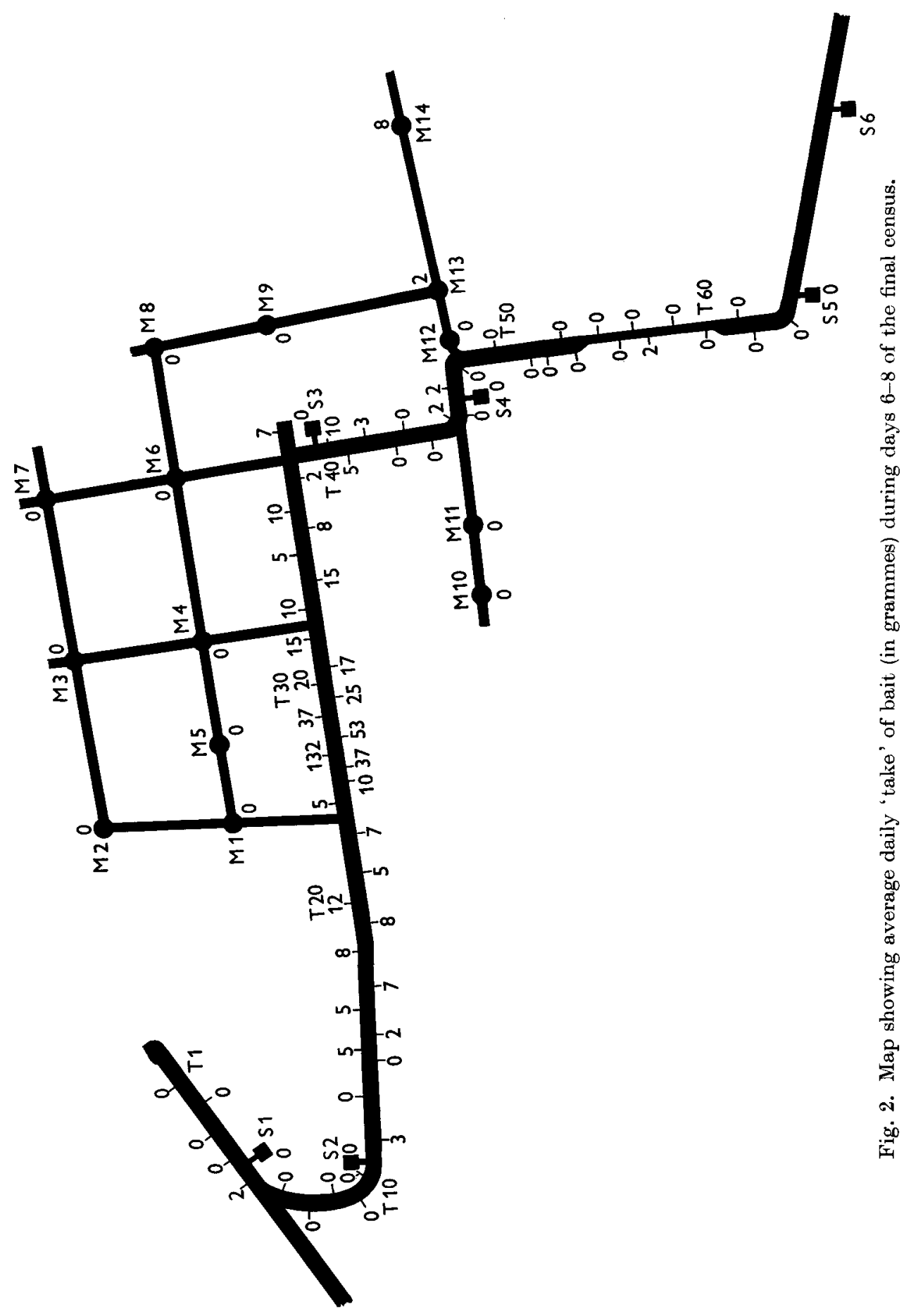


to the very few animals that were found at the manholes during the earlier poison treatments.

Sixteen of the rats that were recovered were males. Their weights and that of another male killed 2 days previously by a sewerman were (to the nearest $5 \mathrm{~g}$.) : 30 , $30,40,40,45,45,45,60,60,60,90,305,380,400,410$ and $475 \mathrm{~g}$. Four of the thirteen females weighed each about $30 \mathrm{~g}$. The details of the other nine are as follows:

\begin{tabular}{cl}
$\begin{array}{c}\text { Weight } \\
(\mathrm{g} .)\end{array}$ & \multicolumn{1}{c}{ Reproductive condition } \\
240 & Six embryos on left; 5 right, early \\
260 & 4 left, 5 right, very early \\
265 & Lactating \\
305 & \\
325 & Lactating \\
340 & Lactating \\
375 & Lactating \\
405 & Lactating \\
425 & 6 left, 5 right, early and lactating
\end{tabular}

All these weights should be reduced by rather less than $10 \%$ to allow for the fact that the bodies were wet when examined.

The time-table of the main phases of the experiment was as follows:

Bait census of whole system:

6-21 July

First poisoning at the access points:

3-9 Aug.

Second poisoning at the access points:

9-14 Aug.

Third poisoning at the access points:

14-23 Aug.

Fourth poisoning at the access points:

23 Aug. -3 Sept.

'Token' census with wheat grains along the main drain:

3-8 Sept.

Fifth poisoning at the access points:

20-27 Sept.

Second 'token' census along the main drain:

29 Sept. -1 Oct.

Sixth poisoning at the access points:

27 Oct. -8 Nov.

Final bait census of whole system:

8-16 Nov.

Final poisoning of the whole system:

16-19 Nov.

\section{DISCUSSION}

There can be no doubt that the failure to bring about a reasonable degree of rat control by poisoning at the manholes and side-entrances was not a result of faulty technique-such as the causing of poison shyness by too frequent treatments. Instead it was because the population present at the final census rarely ranged as far as the access points. This follows from the census records at the latter, from the adequate 'takes' of poison bait whenever prebait 'takes' occurred, and from the reasonable success of the final treatment (as evidenced by the dead rats collected) when poison was laid along the sewer itself.

It is obvious, too, that whatever part territorial behaviour may have played in restricting the range of the colony or colonies between $\mathrm{S} 2$ and $\mathrm{S} 3$ this stretch of the main drain held attractions for rats. It must have provided a fair amount of 
harbourage in the form of breaks in the connecting drains (for the sewer itself was in good repair), and there must have been a continuous supply of food. This could only have come from private houses, small shops and cafés and one or two small factories-for the main drain had a summit at S3 and carried away only the effluent originating along its length and in neighbouring side streets.

The need (dictated by the aim of the study) to confine census baiting to the access points made it impossible to ascertain just how many rats were missed by the early poison treatments, and what was the course of events between S 2 and S 3 in the ensuing weeks. For this reason the body weights and reproductive condition of the rats picked up at the end of the experiment are of special interest.

A striking feature of the data is the absence of males weighing between 90 and $305 \mathrm{~g}$. and of females between 60 and $240 \mathrm{~g}$. If rats of these weight ranges were present in the population it might be expected that one or two would occur even in a sample as small as 30 ; for there is no obvious reason why, in particular, rats of medium size should have escaped being poisoned, or alternatively, why their bodies should have been overlooked in the pick-up. It is tempting, therefore, to take the figures at their face value. The fact that all but one of the nine females were pregnant or lactating and that no young adults were present then suggests at least three possibilities.

First, it could have happened that the original population was eliminated (or almost so) by the early poison treatments the last of which ended on 3 September, and that a new population of adult or even pregnant rats invaded the system and began to breed. If this occurred it must have started immediately-for though reliable figures for the weights reached in the wild by $R$. norvegicus at different ages-especially rats living in sewers-are not available, it may be hazarded that the $90 \mathrm{~g}$. males were about 9-10 weeks old and could not therefore have been conceived much later than mid-August. Moreover, the test with wheat grains on 3-5 September, showed that there were several rats present by then.

It is unlikely that considerable invasion could have occurred from adjacent sewers without being detected by the census baits at the access points. Any migration therefore probably came from the surface. Unfortunately, circumstances did not permit a thorough investigation of the extent of rat traffic between the surface and the sewer; but no above-ground reservoir of rats was believed to exist. During the 4 months of the observations the Local Health Department was notified of, and dealt satisfactorily with, nine cases of rat infestation in the locality, the majority of which were associated with defective drains.

If reinvasion occurred, it is difficult to see why the new population could not be persuaded (like the previous one) to visit the manholes, why it included few or no young adults or subadults and why it happened to establish itself so quickly in a part of the sewer where, from past experience and from the data of the first census, it could have been predicted that survivors from the poison treatment would be found.

Secondly, the absence of rats of medium weight could also be understood if, for some months previous to August, very few families had been reared to maturity in the sewer-possibly through shortage of food-and if successful breeding had 
recommenced when competition for food was reduced as a result of the control treatment at the manholes. However, if this happened, it is surprising that the survivors did not immediately begin to forage further afield.

Thirdly, it is possible that when colonies of rats survive between manholes, further poisoning at the access points tends mainly to remove young adults. This could be the case if, through shortage of food or harbourage, there were a tendency in a growing population, for young adults to be the first to leave. Not enough is known about social behaviour in wild $R$. norvegicus to lend support to this suggestion, but it seems not improbable.

In general, the investigation has shown that present methods of poisoning at the access points cannot be expected always to give complete control however much time and care is employed and that some method must be devised to convey poison to the colonies living between manholes. It has already been recommended (Bentley et al. 1955) that where sewers can be walked, poisoning along them is desirable. In narrower sewers where manholes are far apart and frequent road subsidence from rat activity occurs, the insertion of extra, baitable, manholes is the cheapest, long-term solution in sight.

\section{SUMMARY}

1. The rat population of a main sewer was studied by means of census baits.

2. In a series of poison treatments extending over 4-5 months all rats visiting the access points were eliminated.

3. At the end of this period the population was $40-65 \%$ of what it was at the beginning.

This work would not have been possible without the generous assistance once more of Mr A. R. J. Vickery, Assistant District Engineer of the Chief Engineer's Department of the London County Council and members of his staff, and without the ready co-operation of the Borough Engineer, the Medical Officer of Health and the Chief Health Inspector of the Metropolitan Borough of Bethnal Green, through which area the sewer ran.

\section{REFERENCES}

Bentley, E. W. (1955). Sewer rat populations and their control. Advanc. Sci. 12, 105. Bentley, E. W. (1956). Recent progress in the control of rats in sewers. Sanitarian, 64, 392.

Bentley, E. W., Bathard, A. H. \& Hammond, L. E. (1955). Some observations on a rat population in a sewer. Ann. appl. Biol. 43, 485.

Peters, H. (1951). Die Wanderratte in der Kanalisation. Gesundheitsing. 72, 236.

(MS. received for publication 4. IV. 57) 